\title{
Analysis of genotype $\times$ environment interaction for seed yield in spring oilseed rape using the AMMI model
}

Crop Breeding and Applied Biotechnology 20(1): e26502012, 2020 Brazilian Society of Plant Breeding. Printed in Brazil http://dx.doi.org/10.1590/198470332020v20n1a2

\section{Kayvan Agahi ${ }^{1}$, Jafar Ahmadi ${ }^{*}$, Hassan Amiri Oghan ${ }^{2}$, Mohammad Hossein Fotokian ${ }^{3}$ and Sedigheh Fabriki Orang ${ }^{1}$}

\begin{abstract}
In order to assess the genotype by environment interaction (GE) and select genotypes to exploit narrow and broad adaptations, twenty-two spring oilseed rape genotypes were subjected to field surveys at five experimental sites in the 2015-16 and 2016-17 growing seasons. Plant materials were sown in the form of a randomized complete block design with three replicates. The additive main effects and multiplicative interaction (AMMI) model was used to determine the genotype, environment, and GE effects. The sum of squares (SS) for the first three interaction principal components was very close to the SS for the GE signal; therefore, AMMI3 was diagnosed as the most accurate model to optimize predictive accuracy. Hyola 401 had the highest broad adaptability. In total, the chances of increasing yield were $55.80 \%$ from broad adaptations, $26.73 \%$ from narrow adaptations with 4 mega-environments, and an additional $17.47 \%$ from narrow adaptations with 5 mega-environments.
\end{abstract}

Keywords: Broad adaptation, mega-environment, narrow adaptation, yield stability.

\section{INTRODUCTION}

Oilseed rape (Brassica napus L.) is an important crop that is grown worldwide for oil extraction. In Iran, due to a lack of local production, a considerable portion of edible oil needs is met through imports. The Iranian government has recently considered oilseed rape as the leading prospect for increasing oil production and reducing dependence on imports. Agricultural data show that, in 2017, $12,8567 \mathrm{t}$ of oilseed rape was harvested in Iran from an area of about 70,444 ha, for an average mean yield of about $1825 \mathrm{~kg} \mathrm{ha}^{-1}$ (FAO 2018). Thus, there is a serious need to increase domestic oilseed production. As a result, several breeding programs have been designed to increase oilseed rape performance. The challenge is that yield is a complex trait that is controlled by several genes and is strongly influenced by the environment. Field crops may exhibit significantly different performances across different environments, an effect identified as the genotype by environment interaction (GE). Consequently, the GE must be evaluated prior to releasing newly developed and/or introduced cultivars. The goal is to identify genotypes that show both high mean performance and high stability (i.e. less fluctuation) in multi-environment trials (MET).

According to Yan et al. (2007), in MET, the yield of each genotype is influenced by the effects of the environment (E), genotype (G), and GE. Among these,
*Corresponding author: E-mail: j.ahmadi@eng.ikiu.ac.ir (D) ORCID: 0000-0002-2709-9392

Received: 12 March 2019

Accepted: 05 July 2019 Published: 13 February 2020

${ }^{1}$ Imam Khomeini International University, 34148-96818, Qazvin, Iran ${ }^{2}$ Seed and Plant Improvement Institute, Agricultural Research, Education and Extension Organization, 31359-33151, Karaj, Iran

${ }^{3}$ College of Agriculture, Shahed University, 33191-18651, Tehran, Iran 


\section{K Agahi et al.}

only the $G$ and $G E$ are significant for evaluating new cultivars. The GE weakens the relationship between phenotype and genotype and thus reduces the efficiency of selection (Kebede B and Getahun 2017). In addition, the GE cannot be explained independently through the $\mathrm{G}$ or $\mathrm{E}$. Therefore, several statistical methods, such as parametric and nonparametric approaches, have been developed to analyze the GE across environments (Yan et al. 2007). Among parametric methods, the additive main effects and multiplicative interaction (AMMI) is an effective multivariate model that is frequently used by plant breeders and agricultural researchers to estimate crop adaptability and stability, as well as to detect megaenvironments (Shahriari et al. 2018). The AMMI model came to the attention of agricultural researchers particularly through the publications of Kempton (1984) and Zobel et al. (1988). Since then, AMMI has become a popular statistical tool among agricultural researchers for the purposes of understanding the GE and for gaining accuracy in selection if stable jenotypes in many crops, such as wheat (Singh et al. 2019), barley (Kiliç 2014), cassava (Morais et al. 2017), and oilseed rape (Marjanović-Jeromela et al. 2011; Zali et al. 2016; Nowosad et al. 2016) genotypes.

AMMI uses principal component analysis (PCA) for visualizing the GE in what is known as a biplot diagram (Sadeghzadeh et al. 2018). The method is used to identify genotypes with a high mean yield and considerable adaptability to the desired area through analysis of variance (ANOVA) and mega-environment delineation (Gauch 2013; Hongyu et al. 2014). Literature shows that AMMI analysis of MET data includes four major steps: 1 - analysis of variance, 2 - model diagnosis, 3 - mega-environment delineation, and 4 - selection and recommendation (Haider et al. 2017; Siger et al. 2018; Sousa et al. 2018).

Iran, which has diverse agro-ecological regions, needs to identify cultivars or genotypes suitable for each region and increase the area and production of oilseed rape. Therefore, the objective of this study was to evaluate the adaptability and stability of the seed yield of 22 oilseed rape genotypes across five different regions of Iran using the AMMI model.

\section{MATERIAL AND METHODS}

Plant materials of this study consisted of 22 genotypes of spring oilseed rape (comprised of 21 advanced lines and one check variety) that were the object of field surveys at five experimental sites over two growing seasons (2015-16 and 2016-17), resulting in 10 environments (combinations of locations and years). These 22 genotypes are in fact the top genotypes selected from a rapeseed population consisting of 32 genotypes (30 promising lines and two control varieties, RGS003 and Delgan), which were subjected to a one-year preliminary experiment in 4 warm regions of Iran. Of these 22 genotypes, those with top performance and yield stability will be selected and registered as new cultivars in the Variety Release Committee of Iran and will be available to farmers. The codes assigned to each genotype, along with corresponding pedigrees, are detailed in Table 1. The locations consisted of Sari, Gorgan, Borazjan, Dezful, and Zabol. More information on these locations has been provided in Table 2. The selected locations cover different types of weather conditions, including warm and humid, and warm and arid climates (the northern, southern, and western parts of Iran). In each environment (location-year combination), plant materials were sown in the form of a randomized complete block statistical design, with three replicates. Each genotype was cultivated on a $5 \times 1.2 \mathrm{~m}$ plot consisting of four rows spaced at 30 centimeters. Planting time and crop maintenance stages were based on the local agro-ecological conditions at each test location. Fertilization was carried out based on the results of soil analysis. At harvest time, seed yield was measured on a plot basis in each test environment and converted to $\mathrm{kg} \mathrm{ha}^{-1}$ for statistical analyses.

The AMMI model was used to determine the G, E, and GE effects. The AMMI model for yield of the i-th genotype in the j-th environment is:

$$
Y_{g e}=\mu+\alpha_{g}+\beta_{e}+\Sigma_{n} \lambda_{n} \delta_{g n} \delta_{e n}+\rho_{g e}[1]
$$

where $Y_{g e}$ is the yield of genotype $g$ in environment $\mathrm{e} ; \mu$ is the grand mean; $\alpha_{g}$ is the genotype deviation from the grand mean; $\beta_{e}$ is the environment deviation; $\lambda_{n}$ is the singular value for principal component (PC) $n$ and, correspondingly, $\lambda_{n}^{2}$ is its eigenvalue; $\delta_{g n}$ is the eigenvector value for genotype $g$ and component $n ; \delta_{e n}$ is the eigenvector value for environment e and component $\mathrm{n}$, with both eigenvectors scaled as unit vectors; and $\rho_{g e}$ is the residual.

AMMI analysis was performed using AMMISOFT version 1.0, available at <https://scs.cals.cornell.edu/people/ hugh-gauch/>. AMMI1 graph was prepared using Microsoft Excel 2013. Cross validation analysis was performed using MATH-MODEL3.0. 


\section{RESULTS AND DISCUSSION}

\section{Analysis of variance}

The mean total yield of the genotypes studied ranged from 1953 to $2665 \mathrm{~kg} \mathrm{ha}^{-1}$ throughout the environments, with an average of $2276 \mathrm{~kg} \mathrm{ha}^{-1}$ (Table 1). G15 had the highest mean yield, and G2 had the lowest. The average yield per environment ranged from $686 \mathrm{~kg} \mathrm{ha}^{-1}$ (G21 in E6) to $3869 \mathrm{~kg} \mathrm{ha}^{-1}$ (G22 in E5). Most of the genotypes had maximum yield in the E8 and E5 environments, while the lowest average yield of the genotypes was in E2 (Table 1).

In the present study, the responses of oilseed rape genotypes to environmental conditions were investigated by the AMMI model based on variations in seed yield. The genotypes included in this study have had considerable yield potential. The results of AMMI analysis for seed performance of 22 oilseed rape genotypes studied across ten environments have been summarized in Table 3. In the first step, the worthiness of the analysis was assessed. According to Gauch (2013), AMMI analysis is likely worthwhile if the sum of squares (SS) for the GE signal ( $\mathrm{SSGE}_{\mathrm{s}}$ ) is at least as large as that for SSG. In the present study, the $\operatorname{SSGE}_{S}$ (61211676.53) was approximately 1.9 times as large as SSG (32673639.88), indicating that AMMI analysis was likely to be worthwhile. In addition, the ANOVA table shows that $57.04 \%$ of the SS treatment was due to SSE and SSGE $_{\mathrm{N}}$ (sum of squares of GE noise), whereas $42.96 \%$ was due to SSG and SSGE ${ }_{S}$. The results also indicated that $48.11 \%$ of the treatment was due to environmental effects, whereas $14.95 \%$ belonged to genotypic effects and $36.94 \%$ to the GE effects. Hence, the environment contributed more to the total variation in seed yield than the $G$ and GE.

Marjanović-Jeromela et al. (2011) assessed the genotype by environment interaction for seed yield per plant in 19 rapeseed cultivars grown in northern Serbia by the AMMI model and found that $72.49 \%$ of the total yield variation was explained by the environment, $7.71 \%$ by differences between genotypes, and $19.09 \%$ by the genotype by environment interaction. Zali et al. (2016) estimated grain yield stability of six rapeseed genotypes using the AMMI model over two consecutive growing seasons and found that the $\mathrm{E}, \mathrm{GE}$, and $\mathrm{G}$ explained $79.98 \%, 13.83 \%$, and $6.19 \%$ of total yield

Table 1. Name, code, and type of genotype tested, along with the mean yield of each genotype in each of the environments tested

\begin{tabular}{|c|c|c|c|c|c|c|c|c|c|c|c|c|c|}
\hline \multirow{2}{*}{ Name } & \multirow{2}{*}{ Code } & \multirow{2}{*}{ Pedigree } & \multicolumn{10}{|c|}{ Mean seed yield $\left(\mathrm{kg} \mathrm{ha}^{-1}\right)$} & \multirow{2}{*}{$\begin{array}{c}\text { Mean } \\
\left(\mathrm{kg} \mathrm{ha}^{-1}\right)\end{array}$} \\
\hline & & & E1 & E2 & E3 & $\mathrm{E} 4$ & E5 & E6 & E7 & E8 & E9 & E10 & \\
\hline SAN34 & G1 & Sarigol $\times$ Zafar & 2023 & 1010 & 1853 & 2757 & 2440 & 1654 & 1040 & 1976 & 2595 & 2491 & 1984 \\
\hline SAN35 & $\mathrm{G} 2$ & Dalgan × Zafar & 2471 & 1028 & 1388 & 2580 & 2208 & 1242 & 1585 & 2760 & 2190 & 2075 & 1953 \\
\hline SAN36 & G3 & Zafar & 1671 & 1090 & 1701 & 2903 & 2788 & 1475 & 1647 & 2170 & 2833 & 1660 & 1994 \\
\hline SAN37 & G4 & Dalgan & 2354 & 1236 & 2090 & 2524 & 2205 & 1358 & 1792 & 2647 & 2193 & 1643 & 2004 \\
\hline SAN38 & G5 & Sarigol & 2001 & 1280 & 2423 & 2433 & 2715 & 1618 & 1837 & 2833 & 2109 & 2078 & 2133 \\
\hline SAN39 & G6 & Zarfam× L400 & 2744 & 1412 & 2752 & 2752 & 2863 & 1692 & 1969 & 1917 & 2675 & 3254 & 2403 \\
\hline SAN40 & G7 & RGSO03 (check) & 2326 & 1407 & 2491 & 2773 & 2131 & 1929 & 1675 & 2871 & 2724 & 2396 & 2273 \\
\hline SAN41 & G8 & Talaye $\times$ Zafar & 2963 & 1095 & 2111 & 2480 & 2183 & 1692 & 1652 & 2571 & 2287 & 1607 & 2064 \\
\hline SAN42 & G9 & Dalgan $\times$ Zarfam & 1765 & 1252 & 1984 & 2056 & 3048 & 1787 & 1809 & 3480 & 2232 & 1795 & 2121 \\
\hline SAN43 & G10 & $\mathrm{L} 56 \times \mathrm{L} 300$ & 1605 & 1917 & 2354 & 2487 & 2579 & 1814 & 2474 & 2833 & 2077 & 2368 & 2251 \\
\hline SAN44 & G11 & Dalgan × L17 & 2185 & 1463 & 1698 & 2383 & 2905 & 1581 & 1654 & 2404 & 2122 & 1961 & 2036 \\
\hline SAN45 & G12 & L400 × Sarigol & 1693 & 1729 & 2064 & 2685 & 2683 & 2008 & 2189 & 2671 & 2753 & 3276 & 2375 \\
\hline SAN46 & G13 & $\mathrm{L} 19 \times \mathrm{L} 22$ & 2560 & 1324 & 2214 & 2650 & 3098 & 1897 & 1830 & 2931 & 2740 & 1841 & 2309 \\
\hline SAN47 & G14 & L19× L400 & 3817 & 1867 & 2147 & 2961 & 3423 & 2068 & 2149 & 2467 & 2899 & 2411 & 2621 \\
\hline SAN48 & G15 & Hyola 401 & 2746 & 2089 & 2413 & 2607 & 2843 & 2696 & 2653 & 3122 & 3063 & 2412 & 2665 \\
\hline SAN49 & G16 & Aagamax & 2974 & 1482 & 2750 & 2424 & 2666 & 2185 & 2845 & 2964 & 2979 & 1955 & 2522 \\
\hline SAN50 & G17 & Salsa cl & 2002 & 1476 & 2656 & 2128 & 3120 & 2004 & 1989 & 2952 & 2188 & 2965 & 2348 \\
\hline SAN51 & G18 & Trapper & 2054 & 1564 & 2279 & 2939 & 3316 & 2051 & 1955 & 2779 & 2999 & 2496 & 2443 \\
\hline SAN52 & G19 & Solar cl & 1951 & 1856 & 2202 & 2563 & 3347 & 2247 & 2435 & 3626 & 2245 & 2930 & 2540 \\
\hline SAN53 & G20 & Smilla & 2192 & 1776 & 2491 & 1967 & 3414 & 1957 & 2401 & 2949 & 2221 & 2171 & 2354 \\
\hline SAN54 & G21 & Makro & 1222 & 1762 & 1920 & 2713 & 3167 & 686 & 2352 & 2111 & 2862 & 2149 & 2094 \\
\hline SAN55 & G22 & Belinda & 2494 & 1484 & 2439 & 2460 & 3869 & 3010 & 2255 & 3421 & 2230 & 2230 & 2589 \\
\hline Mean & & & 2264 & 1848 & 1482 & 2008 & 2864 & 2280 & 2556 & 2510 & 2201 & 2748 & 2276 \\
\hline
\end{tabular}

E1-E10: Environments 1 to 10 
variation, respectively. Likewise, Nowosad et al. (2016) assessed the GE pattern for seed yield in 25 rapeseed cultivars grown in five localities of West Poland by the AMMI model and found that $69.82 \%, 13.67 \%$, and $8.15 \%$ of the total yield variation was explained by the E, G, and GE effects, respectively. Thus, they also found that rapeseed yield was highly influenced by environmental factors.

The results of research by Tadesse et al. (2018) on 17 Brassica carinata advanced genotypes across 6 environments showed that environmental effects were responsible for more than $79 \%$ of the total variation, while $\mathrm{G}$ accounted for $4.78 \%$ and the GE for $15.55 \%$. Marjanović-Jeromela et al. (2011) performed AMMI analysis over an oilseed rape population consisting of 19 genotypes and showed that $72.49 \%$ of the total variation in seed yield was due to environmental effects, while the G accounted for merely $2.65 \%$ and the GE for $9.40 \%$. Shahriari et al. (2018) proposed that in MET data, the contribution of the G, E, and GE effects to the total variation can be considered as $20 \%, 70 \%$, and $10 \%$, respectively.

The first six significant principal components accounted for $92.71 \%$ of the total variation in the GE. The first PCA explained $29.20 \%$ of the variation from the GE, while PCA2, PCA3, PCA4, PCA5, and PCA6 accounted for 25.13, 13.38, $10.59,9.06$, and $5.35 \%$, respectively. The effect of the GE was 2.5 times greater than the effect of genotype (Table 3).

\section{Model diagnosis}

Model selection is one of the most important steps in AMMI analysis. As discussed by Gauch (2013), in most published papers related to AMMI analysis, no model diagnosis was performed. Instead, AMMI1 was taken as an automatic default,

Table 2. Description of the experimental sites related to regional testing of the yield of 22 oilseed rape genotypes

\begin{tabular}{|c|c|c|c|c|c|c|c|c|c|}
\hline \multirow{2}{*}{ Row } & \multirow{2}{*}{ Site } & \multirow{2}{*}{ Year } & \multirow{2}{*}{ Code } & \multicolumn{2}{|c|}{ Geographical position } & \multirow{2}{*}{$\begin{array}{c}\text { Altitude } \\
(\mathrm{m})\end{array}$} & \multirow{2}{*}{ Average rainfall $(\mathrm{mm})$} & \multicolumn{2}{|c|}{ Temperature (o $\mathrm{C}$ ) } \\
\hline & & & & Lat $(\mathrm{N})$ & Long (E) & & & Min. & Max. \\
\hline \multirow[t]{2}{*}{1} & Borazjan & $2015-16$ & E1 & 29.214218 & 51.227538 & 77 & 5.20 & 8.23 & 40.27 \\
\hline & & $2016-17$ & E2 & & & & 15.15 & 9.48 & 40.58 \\
\hline \multirow[t]{2}{*}{2} & Dezful & $2015-16$ & E3 & 32.262709 & 48.414657 & 86 & 24.80 & 11.88 & 37.63 \\
\hline & & $2016-17$ & E4 & & & & 29.62 & 10.65 & 37.65 \\
\hline 3 & Gorgan & $2015-16$ & E5 & 36.896291 & 54.420750 & -3 & 48.44 & 5.90 & 32.73 \\
\hline 4 & & $2016-17$ & E8 & & & & 41.10 & 8.73 & 31.55 \\
\hline \multirow[t]{2}{*}{5} & Zabol & $2015-16$ & E9 & 31.019038 & 61.489223 & 481 & 3.25 & 10.41 & 38.17 \\
\hline & & 2016-17 & E10 & & & & 1.67 & 8.32 & 38.08 \\
\hline
\end{tabular}

Table 3. AMMI ANOVA for seed yield of the 22 oilseed rape genotypes across 10 environments

\begin{tabular}{|c|c|c|c|c|c|}
\hline Source & df & SS & MS & \% Treatment & $\% \mathrm{GE}$ \\
\hline Total & 659 & 267991573.41 & 406664.00 & & \\
\hline Treatment & 219 & 218563760.74 & $998008.04^{* * *}$ & & \\
\hline Genotype & 21 & 32673639.88 & $1555887.61^{* * *}$ & 14.95 & \\
\hline Environment & 9 & 105157239.00 & $11684137.67^{* * *}$ & 48.11 & \\
\hline GE Interaction & 189 & 80732881.86 & $427158.11^{* * *}$ & 36.94 & \\
\hline PC1 & 29 & 23577723.39 & $813024.94^{* * *}$ & & 29.20 \\
\hline PC4 & 23 & 8553268.48 & $371881.24^{* * *}$ & & 10.59 \\
\hline PC5 & 21 & 7316684.42 & $348413.54^{* * *}$ & & 9.06 \\
\hline PC6 & 19 & 4318865.56 & $227308.71^{* *}$ & & 5.35 \\
\hline Residual & 45 & 5878859.49 & 130641.32 & & 14.41 \\
\hline Error & 440 & 49427812.67 & 112335.94 & & \\
\hline
\end{tabular}


because convenient two-dimensional graphs can be based on such models. Model diagnosis matters because selection of the best AMMI model will increase predictive accuracy.

AMMI comprises a family of models, with AMMIO (the merely additive model), AMMI1, AMMI2, and so on. Statistical significance, agricultural interpretability, and predictive accuracy are the three criteria for model diagnosis. Predictive accuracy is the most important of these three criteria (Gauch 2013) and it has mostly been assessed using cross-validation. In this method, for each member of the family of AMMI models, the Root Mean Square Prediction Difference (RMSPD) between validation data and model estimates is calculated. Subsequently, maximum predictive accuracy will belong to that model which has the lowest RMSPD value.

An alternative to cross-validation, which has been used in this study, is to estimate the SS for $\mathrm{GE}_{\mathrm{s}}$. As proposed by Gauch (2013), this method is computationally trivial and yet rather reliable. This method is actually equal to retaining as many PCs as needed for the sum of their eigenvalues to approximate the $\mathrm{SSGE}_{\mathrm{s}}$, namely 61211676.53 As shown in Table 3, the SSGE, SSGE$_{N^{\prime}}$ and $\mathrm{SSGE}_{\mathrm{S}}$ were estimated to be $80,732,881.86,19,521,205.34$ (or $24.18 \%$ of SSGE), and $61,211,676.53$ (or $75.82 \%$ of SSGE). From Table 3, the cumulative sum of squares (CSS) for the first four PCs (AMMI models) are $23,577,723.39,43,861,701.2,54,665,203.93$, and 63,218,472.41, respectively. Among these models, the CSS for PC3 is close to SSGE$_{s}$, and it is better not to add PC4 with its SS of 8,553,268.48. In addition, AMMI3 was superior to AMMI4 with regard to the fact that early PCs capture a signal, whereas late PCs capture noise; discarding noise improves accuracy and increases repeatability. Hence, the model diagnosis for optimizing predictive accuracy is AMMI3.

It may be imagined that a model lower than AMMI3 (for example AMMI1) would be more appropriate because of practical constraints that require few mega-environments. However, it should be noted that the situation of fewer mega-environments is justified when more emphasis is placed on the use of broad adaptation. For our dataset, however, the $\mathrm{SSGE}_{\mathrm{s}}$ was 1.87 times that for GEN main effects, showing that narrow adaptation was more important. As shown in Table 4, AMMI1 leads to the formation of 4 mega-environments, whereas we will have 5 mega-environments with AMMI3, which does not different much from the number of AMMI1. Moreover, Table 4 shows a maximum man yield of $2972 \mathrm{~kg} \mathrm{ha}^{-1}$ called "Ockham's hill" for yield as a function of the number of mega-environments. In this Table, from left to right, accuracy initially increases while mostly signal is captured, and afterward decreases while mostly noise is captured, resulting in the formation of "Ockham's hill". To the left of Ockham's hill, models are less accurate because they underfit signal. Likewise, models placed on the right side are also less accurate because they overfit noise. As can be seen, the maximum yield of $2972 \mathrm{~kg} \mathrm{ha}^{-1}$ for AMMI3 was at 5 mega-environments, while fewer mega-environments underfit signal and more mega-environments overfit noise. The above results justify the use of AMMI3 for optimizing predictive accuracy instead of AMMI4 or AMMI1.

We also performed cross-validation analysis. The results showed that AMMI4 followed by AMMI3 had the lowest RMSPDs (data not shown). However, as explained above, AMMI3 was selected with regard to the fact that, in general, it is preferable to select the simpler model (i.e., AMMI3 rather than AMMI4) when two successive members of the family of models are nearly tied for maximizing predictive accuracy.

Table 4. Winning genotypes and the consequent numbers of mega-environments for the AMMI family of models for the oilseed rape dataset

\begin{tabular}{|c|c|c|c|c|c|c|c|c|c|c|c|}
\hline \multirow{2}{*}{ Genotype } & \multirow{2}{*}{ Yield } & \multirow{2}{*}{ PC1 } & \multicolumn{9}{|c|}{ AMMI family of models } \\
\hline & & & 0 & 1 & 2 & 3 & 4 & 5 & 6 & 7 & $\mathrm{~F}$ \\
\hline G19 & 2540.3 & 19.7 & & 3 & 3 & 2 & & & 2 & 1 & 1 \\
\hline G22 & 2589.2 & 14.0 & & 2 & 2 & 3 & 3 & 3 & 2 & 2 & 2 \\
\hline G12 & 2375.0 & 6.9 & & & 1 & & & & & 1 & 1 \\
\hline G18 & 2443.2 & 1.2 & & & & & & 1 & 1 & & \\
\hline G15 & 2664.5 & -0.3 & 10 & 2 & 1 & 1 & 3 & 2 & & 3 & 2 \\
\hline G14 & 2621.0 & -21.3 & & 3 & 3 & 3 & 3 & 2 & 2 & 2 & 2 \\
\hline Mean yield & 2519.8 & & 2664.4 & 2850.4 & 2965.6 & 2972.0 & 2961.0 & 2913.3 & 2868.2 & 2873.6 & 2862.9 \\
\hline
\end{tabular}

14 other genotypes were not listed as they were not among the winners. 
Table 5. Winning genotypes based on 3 members of the AMMI family of models for the oilseed rape dataset

\begin{tabular}{|c|c|c|c|c|c|c|c|c|c|c|c|c|c|c|}
\hline \multirow{2}{*}{ Environment } & \multirow{2}{*}{ Mean } & \multirow{2}{*}{ PC1 } & \multicolumn{4}{|c|}{ AMMI1 Rank } & \multicolumn{4}{|c|}{ AMMI3 Rank } & \multicolumn{4}{|c|}{ AMMIF Rank } \\
\hline & & & 1 & 2 & 3 & 4 & 1 & 2 & 3 & 4 & 1 & 2 & 3 & 4 \\
\hline E10 & 2747.9 & 21.2 & G19 & $\mathrm{G} 22$ & G15 & G20 & G14 & G6 & G21 & G18 & G14 & G18 & G3 & G7 \\
\hline E5 & 2864.1 & 15.7 & G19 & $\mathrm{G} 22$ & G15 & $\mathrm{G} 20$ & $\mathrm{G} 22$ & G15 & G19 & G16 & $\mathrm{G} 22$ & G15 & G19 & G16 \\
\hline $\mathrm{E} 4$ & 2008.4 & 11.7 & G19 & $\mathrm{G} 22$ & G15 & $\mathrm{G} 20$ & G6 & G12 & G17 & G19 & G12 & G6 & G17 & G19 \\
\hline E3 & 1481.8 & 7.0 & $\mathrm{G} 22$ & G19 & G15 & G16 & G19 & G15 & G18 & G22 & G15 & G10 & G14 & G19 \\
\hline E2 & 1847.8 & 6.9 & $\mathrm{G} 22$ & G19 & G15 & G16 & G14 & G21 & G18 & G6 & G15 & G18 & G16 & G14 \\
\hline E8 & 2509.8 & -16.3 & G14 & G15 & G16 & G6 & $\mathrm{G} 22$ & G19 & G15 & G20 & G16 & G15 & G10 & G19 \\
\hline E7 & 2555.7 & -17.3 & G14 & G15 & G16 & G6 & G19 & $\mathrm{G} 22$ & G15 & G20 & $\mathrm{G} 22$ & G14 & G20 & G19 \\
\hline E1 & 2264.3 & -35.7 & G14 & G6 & G16 & G15 & G14 & G16 & G8 & G15 & G14 & G16 & G8 & G15 \\
\hline
\end{tabular}

In general, AMMI1, the model most suitable for megaenvironment delineation, was used to delineate megaenvironments. However, after identifying the winning genotype in each of the 10 environments by the AMMI model, the most accurate member of this family of models, namely AMMI3, was used to estimate the yields of those winners.

\section{Mega-environment delineation}

Detection of mega-environments is useful in finding general patterns that fit most of the data. Mega-environments are commonly distinguished by having different genotype winners. Table 4 displays the genotype winners and the consequent numbers of mega-environments for AMMI models from AMMIO to AMMIF. The top 4 genotypes in each of the 10 environments have been listed in Table 5 based on the three members of the family of AMMI models. According to Table 5, AMMI1 had 4 winners (i.e., G19, G22, G15, and G14), whereas there were 5 winners according to AMMI3. Also, with the AMMIF model, 7 out of the 22 genotypes won the first rank in at least 1 environment. As shown in the two tables above, there was a greater number of winner genotypes with higher AMMI models, and this implies that a greater number of winner genotypes (and thus a greater number of mega-environments) was associated with more complexity in the AMMI model. Therefore, parsimonious models, such as AMMI1, which are commonly accompanied with more signal in the $\mathrm{GE}$, should be the best for mega-environment delineation.

Figure 1 displays the mean vs. stability view of the AMMI1 biplot, visualizing mega-environments, as well as their winner genotypes. According to Table 5 and Figure 1, four mega-environments were delineated through the AMMI1 model. Mega-environment one consisted of E10, E5, and E4, in which G19 was the winner genotype, whereas E2 and E3 formed mega-environment two, with G22 as the winner genotype. E2 plus E3 were placed in mega-environment three, which had the lowest PC score and was therefore the most stable mega-environment, where G15, the most stable genotype, was the winner. The fourth mega-environment consisted of E7, E8, and E1, in which G14 was the winner genotype.

\section{Selection and recommendation}

As emphasized by Gauch (2013), selection of the best genotypes should ideally be performed with yield estimates 
in the context of a given mega-environment scheme. Furthermore, plant breeders usually pay attention to broad and narrow adaptation for increasing yield. Figure 1 shows that $\mathrm{G} 15$ had the highest mean yield, followed by G14, G22, and G19. Among these, G15, with an PC1 score near 0, was the most stable genotype. The results summarized in Table 4 show the most important aspects of adaptability considered by plant breeders for increasing yield, namely: i) broad adaptations, ii) narrow adaptations that can be exploited with the AMMI1 model (4 mega-environments), and iii) additional narrow adaptations with the AMMI3 model (5 mega-environments). First, the grand mean (2276.10 kg ha$\left.{ }^{1}\right)$, which is practically equal to complete ignorance of both broad and narrow adaptations, was considered as a base. Broad adaptability is achieved when all environments are considered as a single mega-environment, which is equal to exploiting AMMIO. As shown in Table 4, G15 was the winner with AMMIO. Consequently, this genotype had the highest broad adaptability, which gives a yield increase of $2664.4-2276.10=388.30 \mathrm{~kg} \mathrm{ha}^{-1}$. In addition, G19, G22, G15, and G14 showed the highest narrow adaptations, with 4 mega-environments delineated by AMMI1. According to Table 4, exploiting AMMI1 led to an additional yield increase of 2850.4-2664.4 = $186 \mathrm{~kg} \mathrm{ha}^{-1}$. Finally, the use of AMMI3 formed 5 mega-environments, with $\mathrm{G} 22, \mathrm{G} 19, \mathrm{G} 6, \mathrm{G} 15$, and G14 as the winner genotypes. Moreover, utilization of AMMI3, which maximizes possible average yield, resulted in an additional yield increase of $2972-2850.4=121.6 \mathrm{~kg} \mathrm{ha}^{-1}$. Hence, the total yield increase compared to the grand mean (ignorance of both broad and narrow adaptations) was $695.90 \mathrm{~kg} \mathrm{ha}^{-1}$. Therefore, the opportunities to increase yield were $55.80 \%$ from broad adaptations, $26.73 \%$ from narrow adaptations with 4 mega-environments, and an additional $17.47 \%$ from narrow adaptations with five mega-environments. Most of the opportunity from narrow adaptations $(60.47 \%$ ) can be achieved with four mega-environments, which was substantial, compared to that from broad adaptations.

According to Table 4, AMMIF, which represents the information from the yield-trial experiment, led to a yield increase of $586.80 \mathrm{~kg} \mathrm{ha}^{-1}$, whereas AMMI3, representing the additional information from statistical analysis, resulted in a further yield increase of $102.70 \mathrm{~kg} \mathrm{ha}^{-1}$. Therefore, in this study, $85.11 \%$ of the yield gain was due to the experiment, and $14.89 \%$ was due to the analysis. Because of the negligible cost of statistical analysis compared to the cost of a yield trial, AMMI analysis provided a very valuable opportunity for adding value to this study.

\section{Agricultural interpretability}

Genotypes in Table 4 and environments in Table 5 have been listed in their PC1 order, so those at the top and bottom have opposite GE patterns. This means that a genotype at the top of Table 4 had a positive GE with the environment at the top of Table 5 and a negative GE with environments at the bottom of Table 5. Therefore, genotype 19 (G19) had a positive GE with environments E10 and E5 and a negative GE with environments E1 and E7, while G14 (G14) had a positive GE with E1 and E7 and a negative GE with E10 and E5. There was a significant negative correlation between PC1 and the amount of rainfall recorded for each environment $(-0.767)$. This result showed that the AMMI1 megaenvironments had an evident agricultural interpretation in terms of rainfall so that mega-environment 4, with negative PC1 values, had the highest amount of rainfall, whereas other mega-environments had a much more limited rainfall. Correspondingly, Genotype 14 would be more suitable for areas with relatively high rainfall, whereas Genotype 15, 22, and 19 would be suitable for areas with moderate to low atmospheric rainfall. Moreover, except for G10, G15, and G16 (more than $86 \%$ of the genotypes), the mean seed yield was significantly and negatively correlated with the minimum temperature, showing the importance of this environmental parameter in oilseed rape farming.

\section{CONCLUSION}

In this study, mean seed yield was highly affected by environment, genotype by environment interaction, and genotype effects, respectively. Exploiting AMMI analysis resulted in a yield increase of $695.90 \mathrm{~kg} \mathrm{ha}^{-1}$ compared to the grand mean. Of this amount, the contribution of broad adaptation was $72.86 \%$ and narrow adaptation was $27.14 \%$. Furthermore, $14.89 \%$ of yield gain was due to $\mathrm{AMMI}$ analysis providing an opportunity for adding considerable value to the research. The AMMI model had high ability for distinguishing and recommending genotypes with narrow and broad adaptations. In total, G15 (i.e., Hyola 401) had the highest broad adaptability, recommendable for all environments. G22 (i.e., Belinda) was the most suitable genotype for environments E2, E4, and E10; G19 (i.e. Solar cl) for E3 and E5; G6 (i.e., Zarfam × L400) for E6; G15 for E9; and G14 (i.e., L19 × L400) for E1, E7, and E8. 


\section{K Agahi et al.}

\section{ACKNOWLEDGMENTS}

The authors would like to thank Dr. A. Faraji, Dr. W. Ramaye, N. Kh. Kazerani, Dr. H. R Fanaei, and Dr. S. A. Kalantar Ahmadi for conducting experiments and field surveys at experimental sites. We would also like to thank the Seed and Plant Improvement Institute for funding the project.

\section{REFERENCES}

FAO - Food and Agriculture Organization of the United Nations (2018) FAOSTAT statistical database. FAO, Rome.

Gauch HG (2013) A Simple Protocol for AMMI Analysis of Yield Trials. Crop Science 53:1860-1869.

Haider Z, Akhter M, Mahmood A and Khan RAR (2017) Comparison of GGE biplot and AMMI analysis of multi-environment trial (MET) data to assess adaptability and stability of rice genotypes. African Journal of Agricultural Research 12:3542-3548.

Hongyu K, García-Peña M, de Araújo LB and dos Santos Dias CT (2014) Statistical analysis of yield trials by AMMI analysis of genotypex environment interaction. Biometrical letters 51:89-102.

Kebede B A and Getahun A (2017) Adaptability and stability analysis of groundnut genotypes using AMMI model and GGE-biplot. Journal of Crop Science and Biotechnology 20:343-349.

Kempton RA (1984) The use of biplots in interpreting variety by environment interactions. The Journal of Agricultural Science 103:123-135.

Kiliç H (2014) Additive Main Effects and Multiplicative Interactions (AMMI) Analysis of Grain Yield in Barley Genotypes Across Environments. Journal of Agricultural Sciences 20:337-344.

Marjanović-Jeromela A, Nagl N, Gvozdanovi -Varga J, Hristov N, Kondi -Špika A and Marinkovi MVaR (2011) Genotype by environment interaction for seed yield per plant in rapeseed using AMMI model. Pesquisa AgropecuÃiria Brasileira 46:174-181.

Morais LK, Santiago AD and Cavalcante MHB (2017) Phenotypic stability in cassava estimated by the AMMI analysis with supplementary genotypes. Crop Breeding and Applied Biotechnology 17: 366-372.

Nowosad K, Liersch A, Popławska W and Bocianowski J (2016) Genotype by environment interaction for seed yield in rapeseed (Brassica napus L.) using additive main effects and multiplicative interaction model. Euphytica 208:187-194.
Sadeghzadeh B, Mohammadi R, Ahmadi H, Abediasl GR, Ahmadi MM, Mohammadfam M, Bahrami N, Khaledian MS and Naserian AA (2018) GGE biplot and AMMI application in the study of adaptability and grain yield stability of durum lines under dryland conditions. Environmental Stresses in Crop Sciences 11:241-260.

Shahriari Z, Heidari B and Dadkhodaie A (2018) Dissection of genotype $x$ environment interactions for mucilage and seed yield in Plantago species: Application of AMMI and GGE biplot analyses. PLoS ONE 13:e0196095.

Siger A, Michalak M, Lembicz J, Nogala-Kałucka M, Cegielska-Taras T and Szała L (2018) Genotype x environment interaction on tocochromanol and plastochromanol-8 content in seeds of doubled haploids obtained from $\mathrm{F} 1$ hybrid black $\times$ yellow seeds of winter oilseed rape (Brassica napus L.). Journal of the Science of Food and Agriculture 98:3263-3270.

Singh C, Gupta A, Gupta V, Kumar P, Sendhil R, Tyagi B, Singh G, Chatrath $R$ and Singh $G$ (2019) Genotype x environment interaction analysis of multi-environment wheat trials in India using AMMI and GGE biplot models. Crop Breeding and Applied Biotechnology 19: 309-318.

Sousa MBE, Damasceno-Silva KJ, Rocha MDM, Menezes Júnior JÂND and Lima LRL (2018) Genotype By Environment Interaction In Cowpea Lines Using GGE Biplot Method. Revista Caatinga 31:64-71.

Tadesse T, Sefera G and Tekalign A (2018) Genotypes Environment interaction analysis for Ethiopian mustard (Brassica carinata L.) genotypes using AMMI model. Journal of Plant Breeding and Crop Science 10:86-92.

Yan W, Kang MS, Ma B, Woods S and Cornelius PL (2007) GGE Biplot vs. AMMI Analysis of Genotype-by-Environment Data. Crop Science 47:643-653.

Zali H, Sofalian O, Hasanloo T and Asghari A (2016) AMMI and GGE Biplot Analysis of Yield Stability and Drought Tolerance in Brassica napus $\mathrm{L}$. Agricultural Communications 4:1-8.

Zobel RW, Wright MJ and Gauch HG (1988) Statistical Analysis of a Yield Trial. Agronomy Journal 80:388-393.

(cc) EY This is an Open Access article distributed under the terms of the Creative Commons Attribution License, which permits unrestricted use, distribution, and reproduction in any medium, provided the original work is properly cited. 